\title{
PAHs in Sediments along the Semi-closed Areas of Alexandria, Egypt
}

\author{
Mohamed A. Shreadah ${ }^{1}$, Tarek O. Said ${ }^{1 *}$, Mohamed I. Abd El Monem ${ }^{1}$, Eiman M. I. Fathallah ${ }^{2}$, \\ Mohamed E. Mahmoud ${ }^{1}$
}

${ }^{1}$ National Institute of Oceanography and Fisheries, Alexandria, Egypt; ${ }^{2}$ Chemistry Department, Faculty of Science, Alexandria Uni-
versity, Alexandria, Egypt.
Email: tareksaideg@yahoo.co.uk

Received May $9^{\text {th }}, 2011$; revised June $12^{\text {th }}, 2011$; accepted July $25^{\text {th }}, 2011$.

\begin{abstract}
Sediment samples were collected from 49 sampling stations along the semi-closed areas of Alexandria coasts, Egypt. Total concentrations of 15 out of $16 \mathrm{EPA}-\mathrm{PAHs}$ in sediments were varied from 4.2 to $886 \mathrm{ng} \cdot \mathrm{g}^{-1}$ with an average value of $176 \mathrm{ng}^{-1} \mathrm{~g}^{-1}$ (dry wt). The average total organic carbon (TOC) percent was varied from 0.04 to $7.65 \%$. Higher concentration of total pyrolytic hydrocarbons $(\Sigma C O M B)$ than total fossil hydrocarbons ( $\Sigma C O M B)$, declared that atmospheric fall-out is the significant source of PAHs to marine sediments of the semi-closed area of Alexandria. The selected marked compounds and special PAHs compound ratios (phenanthrene/anthracene; fluoranthene/pyrene; $\sum C O M B /$ $\left.\sum E P A-P A H S\right)$ suggest the pyrogenic origins, especially traffic exhausts, are the dominant sources of PAHs in most locations. Interferences of rather petrogenic and pyrolytic PAH contaminations were noticed in the harbours, especially marine area due to petroleum products deliveries and fuel combustion emissions from the ships staying alongside the quays.
\end{abstract}

Keywords: Surface Sediment, PAHs, Alexandria, Egypt, GC-MS

\section{Introduction}

Polycyclic aromatic hydrocarbons (PAHs) have been described as mutagenic, carcinogenic and teratogenic included in the US EPA and the EU priority pollutants list [1]. PAHs solubility decrease with increasing molecular weight [2]. Consequently, the uptake of a contaminant is governed by its bioavailability, and organisms are often enriched in the lower molecular weight PAHs relative to the sediment [3]. Once deposited in sediments, PAHs are less subjected to photochemical or biological oxidation, especially if the sediment is anoxic. Thus, sedimentary PAHs tend to be persistent and may accumulate to high concentrations [4]. Numerous research studies assessed the PAHs inputs in the Northwestern and Central Mediterranean [5]. Conversely, in the Eastern Mediterranean few data have been published on the presence of PAHs in coastal sediments close to point sources (municipal and river discharges, etc.) [6]. In addition, hydrocarbon budgets are available for the Western part of Mediterranean Sea [7], but there is a tremendous lack of information regarding the Southern Mediterranean [8].
This is the first systematic study to be undertaken along the semi-closed areas of Alexandria (Egyptian Mediterranean Sea coast) as a comparative study between four sectors of different identity. Two relevant criteria are used fairly to discriminate between the various natural and anthropogenic hydrocarbon inputs and to evaluate the extent of hydrocarbon pollution in the area and its link to combustion processes and/or releasing of unburned fossil fuels.

\section{Materials and Methods}

A total of 49 surface sediment samples were collected during January 2010 at sites shown in Figure 1. Sediments were collected utilizing a stainless-steel grab. Six grabs were taken from each location from which the top $3 \mathrm{~cm}$ were scooped into pre-cleaned wide-mouth glass bottles, frozen and transported to the laboratory and stored at $-20^{\circ} \mathrm{C}$ until analysis. The samples were analyzed for PAHs following well established techniques [9].

To control the analytical reliability and assure recovery efficiency and accuracy of the results, 6 analyses 


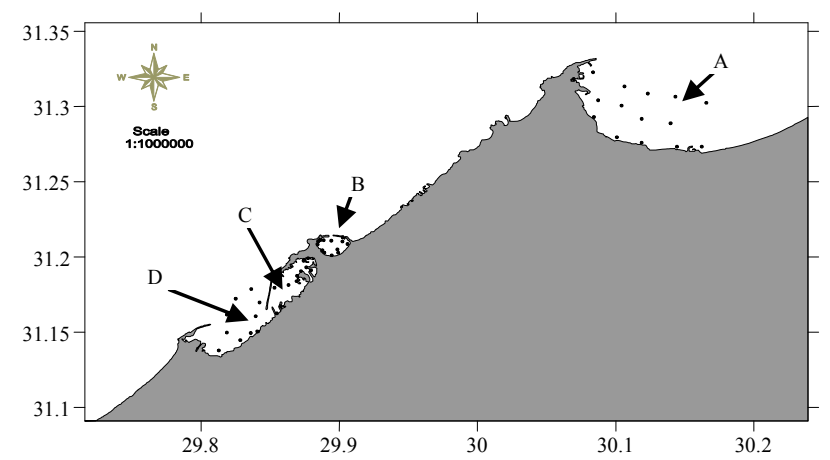

Figure 1. Sampling locations collected from the area of investigation: (A) Abu Qir Bay, (B) Eastern Harbour, (C) Western Harbour and (D) El Max Bay during 2010.

were conducted on PAH compound reference materials, HS-5 (sediments) provided by NRC-IMB of Canada and SRM-2974 (Freeze-dried mussels tissue) (Mytilus edulis) provided by NIST of USA as well as sediment samples of known PAH levels spiked with a mixture consisting of $2 \mu \mathrm{g}$ each of PAHs were analyzed as above to validate the analytical method used in this study. The lowest DL was $0.01 \mu \mathrm{g} / \mathrm{ml}$ for lower molecular mass compounds while indeno[1,2,3-cd]pyrene has the highest at $0.1 \mu \mathrm{g} / \mathrm{ml}$. The recovery efficiency ranged from $92 \%$ to $111 \%$ for HS-5, $88 \%$ to $96 \%$ for SRM-2974 and $93 \%$ to $105 \%$ for the spiked samples. Samples were analyzed by Gas Chromatograph-Mass Spectrometer; GC-MS (Trace DSQ II MS) with fully scanned 50 - 650 Daltons per second mode and $70 \mathrm{eV}$ electron energy for confirmation. $\mathrm{GC} /$ MS is equipped with split/split less injector and a fused silica capillary column; Thermo TR-35 MS (30 m, 0.25 $\mathrm{mm}, 0.25 \mu \mathrm{m}$ ) with $35 \%$ phenyl polysilphenylene-siloxane. Helium was used as carrier gas at $1.5 \mathrm{~mL} \cdot \mathrm{min}^{-1}$. The temperature was programmed from $60^{\circ} \mathrm{C}-100^{\circ} \mathrm{C}$ with rate of $8^{\circ} \mathrm{C} \cdot \mathrm{min}^{-1}$, then maintained at $100^{\circ} \mathrm{C}$ for $1 \mathrm{~min}$, and from $100-300^{\circ} \mathrm{C}$ with rate of $5^{\circ} \mathrm{C} \cdot \mathrm{min}^{-1}$ and was maintained at $300^{\circ} \mathrm{C}$ for $20 \mathrm{~min}$. The injector and detector temperatures were set at $280^{\circ} \mathrm{C}$ and $300^{\circ} \mathrm{C}$, respectively. Three $\mu \mathrm{L}$ volume of each sample was injected in the split less mode and the purge time was $1 \mathrm{~min}$. The response factor of individual PAH compounds to the internal standard was measured and calculated at least three times at the beginning, in the middle, and at the end for each batch of GC injections (15 samples).

\section{Results and Discussion}

Individual and total concentrations, as well as characteristic ratios for the identification of PAH origins are given in Tables 1 and 2. Total PAHs ( $\sum$ PAHs) ranged from 4.2 to 886.08 with an average of $169.37 \mathrm{ng} \cdot \mathrm{g}^{-1}$ dry weight. The highest concentration of total PAHs was recorded in sediments collected from station 28 (Eastern Harbour), followed by that in stations 1, 26 and 34. Lower concentrations were detected in samples of stations $11-15$. In this study, sediment samples collected near the sewage outlet, cities and harbor appeared to have extremely high concentrations of total PAHs. These suggest that PAHs accumulated in Mediterranean Sea sediments came from different sources such as sewage discharge from nearby human activities and fuel combustion emissions. Although the number of PAHs analyzed in any given study may differ, the 15 compounds analyzed herein comprise the vast majority of PAHs found in most estuarine or marine sediments. It has been demonstrated that the nature of the sediment influences the distribution and concentration of PAHs. Sediments with high organic carbon content were characterized with high values of PAHs [10]. However, a moderate correlation of $r=0.646$ was found between $\sum$ PAHs and total organic carbon (TOC) concentrations in the present sediments (Table 1, Figure 2). This may be suggesting that both of direct input and type of sediment found locally would determine the distribution and concentrations of PAHs in sediments. Moreover, the relationship between total PAHs and organic carbon was only significant for highly contaminated sites where total PAH concentration was greater than $2000 \mathrm{ng} \cdot \mathrm{g}^{-1}$ dry wt. In this study, none of the sediment samples had total PAH concentrations more than $2000 \mathrm{ng} \cdot \mathrm{g}^{-1}$ where the samples contain lower TOC.

Chiou et al. [10] found that the high partitioning of PAHs to sedimentary organic matter was mainly due to the significant aromatic fraction of the organic matter. All locations had concentrations lower than the Effects Range-Low (ERL) value (4022 $\left.\mathrm{ng} \cdot \mathrm{g}^{-1}\right)$ suggested by Long et al. [11]. They reported that the concentrations below the ERL value represent a minimal-effect range, i.e. adverse biological effect would rarely be observed below the ERL. On the other hand, if the concentration was higher than the Effects Range-Median (ERM) value $\left(44792 \mathrm{ng} \cdot \mathrm{g}^{-1}\right)$, adverse effects on biological systems will frequently occur. The concentrations of individual PAH recorded in the present study ranged from 4 to $886 \mathrm{ng} \cdot \mathrm{g}^{-1}$, and were much lower than both of the ERL and ERM limit (Table 3 and Figure 3). In addition, similar observations were found relative to the Threshold Effect Level (TEL) and Probable Effect Level (PEL) [11], where Dibenzo(a,h)anthracene, Acenapthylene and acenaphthene have average concentrations $>$ TEL and $<$ PEL (Figure 4). The individual PAH concentrations in this study were also lower than the national sediment quality criteria proposed by USEPA [12] for fluoranthene (3000 $\left.\mathrm{ng} \cdot \mathrm{g}^{-1}\right)$, acenaphthylene $\left(2400 \mathrm{ng} \cdot \mathrm{g}^{-1}\right)$ and phenanthrene $(2400$ $\mathrm{ng} \cdot \mathrm{g}^{-1}$ ). Benzo(a)pyrene (BaP), the most potent carcinogenic PAHs, and the sum of six carcinogenic PAHs 
Table 1. Concentrations (ng/g; dry wt) of PAHs in sediment samples collected from the studied area during 2010.

\begin{tabular}{|c|c|c|c|c|c|c|c|c|c|c|c|c|c|c|}
\hline$\frac{\text { Parameter }}{\text { Site }}$ & PAHs & $\mathrm{Ph} / \mathrm{An}$ & Flu/Py & $\mathrm{BaA} / \mathrm{Chr}$ & $\Sigma \mathrm{CARC}$ & $\%$ CARC & इTFPAH & $\% \Sigma$ TFPAH & $\Sigma \mathrm{COMP}$ & $\% \Sigma \mathrm{COMP}$ & $\begin{array}{c}\Sigma \mathrm{TFPAH} / \\
\Sigma \mathrm{COMP}\end{array}$ & $\mathrm{BkF} / \mathrm{BaP}$ & $\mathrm{BbF} / \mathrm{BaP}$ & $\%$ TOC \\
\hline 1 & 460.96 & 3.05 & 0.33 & 0.71 & 59.42 & 6.41 & 3.27 & 1.67 & 457.69 & 5.65 & 0.01 & 5.18 & 0.55 & 7.65 \\
\hline 2 & 44.57 & 0.05 & 1.00 & 0.29 & 6.62 & 0.71 & 0.99 & 0.51 & 43.58 & 0.54 & 0.02 & 5.47 & 2.29 & 0.62 \\
\hline 3 & 31.88 & 0.11 & 1.00 & 4.00 & 10.79 & 1.16 & 3.86 & 1.97 & 28.02 & 0.35 & 0.14 & 2.52 & 2.19 & 1.13 \\
\hline 4 & 80.22 & 1.62 & 3.00 & 1.00 & 4.70 & 0.51 & 1.60 & 0.82 & 78.62 & 0.97 & 0.02 & 1.09 & 0.14 & 1.11 \\
\hline 5 & 62.16 & 1.62 & 1.00 & 1.00 & 2.45 & 0.26 & 0.59 & 0.30 & 61.57 & 0.76 & 0.01 & 1.08 & 0.85 & 0.23 \\
\hline 6 & 23.96 & 0.08 & 0.00 & 1.00 & 4.46 & 0.48 & 1.16 & 0.59 & 22.79 & 0.28 & 0.05 & 2.29 & 2.00 & 0.31 \\
\hline 7 & 29.13 & 0.06 & 1.00 & 2.00 & 1.15 & 0.12 & 0.67 & 0.34 & 28.46 & 0.35 & 0.02 & 8.83 & 0.17 & 0.49 \\
\hline 8 & 35.83 & 0.06 & 0.33 & 0.50 & 7.28 & 0.78 & 0.29 & 0.15 & 35.53 & 0.44 & 0.01 & 2.17 & 1.83 & 0.12 \\
\hline 9 & 102.18 & 1.62 & 1.00 & 0.50 & 2.77 & 0.30 & 1.49 & 0.76 & 100.69 & 1.24 & 0.01 & 2.89 & 1.56 & 0.43 \\
\hline 10 & 17.08 & 0.06 & 0.00 & 1.00 & 4.30 & 0.46 & 0.70 & 0.36 & 16.38 & 0.20 & 0.04 & 1.60 & 2.80 & 0.04 \\
\hline 11 & 9.30 & 1.67 & 0.00 & 0.00 & 1.70 & 0.18 & 0.30 & 0.15 & 9.00 & 0.11 & 0.03 & 12.40 & 2.00 & 0.35 \\
\hline 12 & 12.60 & 1.00 & NR & NR & 6.60 & 0.71 & 0.50 & 0.26 & 12.10 & 0.15 & 0.04 & 1.96 & 1.56 & 0.31 \\
\hline 13 & 4.20 & 2.00 & NR & 0.00 & 2.20 & 0.24 & 0.20 & 0.10 & 4.00 & 0.05 & 0.05 & 1.00 & 0.57 & 0.12 \\
\hline 14 & 10.60 & 3.50 & NR & 0.20 & 3.90 & 0.42 & 0.20 & 0.10 & 10.40 & 0.13 & 0.02 & 2.00 & 0.32 & 0.23 \\
\hline 15 & 7.40 & 2.33 & NR & 1.00 & 4.60 & 0.50 & 0.50 & 0.26 & 6.90 & 0.09 & 0.07 & 0.33 & 0.50 & 0.23 \\
\hline AV & 62.14 & 1.26 & 0.79 & 0.94 & 8.20 & 0.88 & 1.09 & 0.56 & 61.05 & 0.75 & 0.04 & 3.39 & 1.29 & 0.89 \\
\hline Max & 460.96 & 3.50 & 3.00 & 4.00 & 59.42 & 6.41 & 3.86 & 1.97 & 457.69 & 5.65 & 0.14 & 12.40 & 2.80 & 7.65 \\
\hline Min & 4.20 & 0.05 & 0.00 & 0.00 & 1.15 & 0.12 & 0.20 & 0.10 & 4.00 & 0.05 & 0.01 & 0.33 & 0.14 & 0.04 \\
\hline 16 & 56.9 & 0.71 & 14.00 & 0.04 & 11.37 & 1.23 & 0.58 & 0.30 & 56.37 & 0.70 & 0.01 & 3.70 & 0.29 & 1.56 \\
\hline 17 & 268.9 & 1.62 & 0.37 & 0.02 & 4.52 & 0.49 & 1.32 & 0.67 & 267.58 & 3.30 & 0.00 & 6.57 & 1.43 & 2.24 \\
\hline 18 & 183.7 & 3.44 & 24.50 & 0.09 & 8.30 & 0.89 & 5.40 & 2.76 & 178.30 & 2.20 & 0.03 & 3.00 & 0.86 & 2.13 \\
\hline 19 & 130.20 & 1.62 & 23.00 & 0.33 & 18.33 & 1.98 & 1.86 & 0.95 & 128.33 & 1.58 & 0.01 & 1.74 & 0.32 & 0.59 \\
\hline 20 & 78.00 & 0.03 & 1.31 & 0.33 & 8.94 & 0.96 & 0.98 & 0.50 & 77.01 & 0.95 & 0.01 & 3.68 & 0.27 & 0.45 \\
\hline 21 & 36.40 & 0.03 & 0.95 & 2.00 & 3.91 & 0.42 & 2.94 & 1.50 & 33.46 & 0.41 & 0.09 & 0.87 & 0.61 & 0.21 \\
\hline 22 & 192.79 & 1.62 & 1.36 & 0.63 & 7.02 & 0.76 & 2.08 & 1.06 & 190.71 & 2.35 & 0.01 & 17.44 & 1.19 & 0.44 \\
\hline 23 & 215.11 & 0.02 & 1.42 & 0.04 & 40.46 & 4.36 & 0.70 & 0.36 & 214.41 & 2.65 & 0.00 & 1.72 & 0.02 & 0.69 \\
\hline 24 & 182.12 & 4.87 & 28.00 & 0.50 & 3.93 & 0.42 & 1.28 & 0.65 & 180.84 & 2.23 & 0.01 & 3.61 & 0.48 & 0.50 \\
\hline 25 & 170.94 & 1.61 & 0.00 & 0.50 & 1.36 & 0.15 & 2.82 & 1.44 & 168.12 & 2.07 & 0.02 & 9.00 & 2.33 & 0.49 \\
\hline 26 & 339.13 & 4.86 & 1.31 & 1.33 & 27.17 & 2.93 & 1.19 & 0.61 & 337.94 & 4.17 & 0.00 & 1.84 & 0.19 & 1.02 \\
\hline 27 & 196.88 & 0.04 & 0.01 & 0.02 & 50.15 & 5.41 & 1.75 & 0.90 & 195.13 & 2.41 & 0.01 & 2.06 & 0.08 & 1.22 \\
\hline
\end{tabular}




\begin{tabular}{|c|c|c|c|c|c|c|c|c|c|c|c|c|c|c|}
\hline 28 & 886.1 & 6.04 & 1.24 & 0.85 & 143.47 & 15.46 & 0.57 & 0.29 & 885.51 & 10.93 & 0.00 & 1.95 & 0.03 & 3.18 \\
\hline $\mathrm{AV}$ & 225.9 & 2.0 & 7.5 & 0.5 & 25.3 & 2.7 & 1.8 & 0.9 & 224.1 & 2.8 & 0.0 & 4.4 & 0.6 & 1.1 \\
\hline Max & 886.1 & 6.0 & 28.0 & 2.0 & 143.5 & 15.5 & 5.4 & 2.8 & 885.5 & 10.9 & 0.1 & 17.4 & 2.3 & 3.2 \\
\hline Min & 36.4 & 0.0 & 0.0 & 0.0 & 1.4 & 0.1 & 0.6 & 0.3 & 33.5 & 0.4 & 0.0 & 0.9 & 0.0 & 0.2 \\
\hline 29 & 266.4 & 1.62 & 4.20 & 0.04 & 23.68 & 2.55 & 2.70 & 1.38 & 263.74 & 3.25 & 0.01 & 2.22 & 0.25 & 2.67 \\
\hline 30 & 292.8 & 2.79 & 1.40 & 0.23 & 46.50 & 5.01 & 14.80 & 7.56 & 278.00 & 3.43 & 0.05 & 2.75 & 0.43 & 6.00 \\
\hline 31 & 47.8 & 0.06 & 1.00 & 1.50 & 4.92 & 0.53 & 1.98 & 1.01 & 45.79 & 0.57 & 0.04 & 3.50 & 1.35 & 0.36 \\
\hline 32 & 356.9 & 0.62 & 1.26 & 11.94 & 78.00 & 8.41 & 0.90 & 0.46 & 356.00 & 4.39 & 0.00 & 2.59 & 1.55 & 2.71 \\
\hline 33 & 184.8 & 0.03 & 1.20 & 4.17 & 45.80 & 4.94 & 3.40 & 1.74 & 181.40 & 2.24 & 0.02 & 2.12 & 0.51 & 3.96 \\
\hline 34 & 542.3 & 0.53 & 4.88 & 0.08 & 11.20 & 1.21 & 2.90 & 1.48 & 539.40 & 6.66 & 0.01 & 3.60 & 1.03 & 2.89 \\
\hline 35 & 205.3 & 0.01 & 1.08 & 0.12 & 7.29 & 0.79 & 1.40 & 0.71 & 203.89 & 2.52 & 0.01 & 8.62 & 2.15 & 1.82 \\
\hline 36 & 56.7 & 0.02 & 4.25 & 0.83 & 13.00 & 1.40 & 2.20 & 1.12 & 54.50 & 0.67 & 0.04 & 1.63 & 0.41 & 0.63 \\
\hline 37 & 719.0 & 0.68 & 9.71 & 0.80 & 153.80 & 16.58 & 2.40 & 1.23 & 716.60 & 8.84 & 0.00 & 2.33 & 0.07 & 3.58 \\
\hline 38 & 157.6 & 42.11 & 3.63 & 7.85 & 36.60 & 3.94 & 1.90 & 0.97 & 155.70 & 1.92 & 0.01 & 14.05 & 2.74 & 2.81 \\
\hline 39 & 181.2 & 0.06 & 3.26 & 0.07 & 21.19 & 2.28 & 2.39 & 1.22 & 178.81 & 2.21 & 0.01 & 2.07 & 0.08 & 3.09 \\
\hline AV & 273.7 & 4.4 & 3.3 & 2.5 & 40.2 & 4.3 & 3.4 & 1.7 & 270.3 & 3.3 & 0.0 & 4.1 & 1.0 & 2.8 \\
\hline Max & 719.0 & 42.1 & 9.7 & 11.9 & 153.8 & 16.6 & 14.8 & 7.6 & 716.6 & 8.8 & 0.1 & 14.1 & 2.7 & 6.0 \\
\hline Min & 47.8 & 0.0 & 1.0 & 0.0 & 4.9 & 0.5 & 0.9 & 0.5 & 45.8 & 0.6 & 0.0 & 1.6 & 0.1 & 0.4 \\
\hline 40 & 73.3 & 0.38 & 0.10 & NR & 2.98 & 0.32 & 24.38 & 12.46 & 48.90 & 0.60 & 0.50 & 3.33 & 1.44 & 0.49 \\
\hline 41 & 281.9 & 1.62 & 1.00 & NR & 6.57 & 0.71 & 1.03 & 0.52 & 280.90 & 3.47 & 0.00 & 1.17 & 3.67 & 2.17 \\
\hline 42 & 200.9 & 1.47 & 1.50 & 1.00 & 2.52 & 0.27 & 0.80 & 0.41 & 200.13 & 2.47 & 0.00 & 1.00 & 0.70 & 0.93 \\
\hline 43 & 201.1 & 1.74 & 1.24 & 1.00 & 1.62 & 0.17 & 1.89 & 0.97 & 199.19 & 2.46 & 0.01 & 27.50 & 3.50 & 1.26 \\
\hline 44 & 119.5 & 2.12 & 0.80 & 1.00 & 3.40 & 0.37 & 0.85 & 0.43 & 118.69 & 1.46 & 0.01 & 1.78 & 1.67 & 0.30 \\
\hline 45 & 100.2 & 0.11 & 1.00 & 2.00 & 3.02 & 0.33 & 44.92 & 22.96 & 55.24 & 0.68 & 0.81 & 2.29 & 1.43 & 1.54 \\
\hline 46 & 226.6 & 1.65 & 0.77 & 1.00 & 3.13 & 0.34 & 32.62 & 16.67 & 193.95 & 2.39 & 0.17 & 1.73 & 0.80 & 0.61 \\
\hline 47 & 70.8 & 0.19 & 3.80 & 1.00 & 3.20 & 0.35 & 6.40 & 3.27 & 64.40 & 0.79 & 0.10 & 1.42 & 0.75 & 0.73 \\
\hline 48 & 22.9 & 2.77 & 1.50 & NR & 3.54 & 0.38 & 1.27 & 0.65 & 21.65 & 0.27 & 0.06 & 1.00 & 0.33 & 0.30 \\
\hline 49 & 121.8 & 3.42 & 2.00 & 1.00 & 3.93 & 0.42 & 4.77 & 2.44 & 117.06 & 1.44 & 0.04 & 1.63 & 4.75 & 0.42 \\
\hline $\mathrm{AV}$ & 141.9 & 1.5 & 1.4 & 1.1 & 3.4 & 0.4 & 11.9 & 6.1 & 130.0 & 1.6 & 0.2 & 4.3 & 1.9 & 0.9 \\
\hline Max & 281.9 & 3.4 & 3.8 & 2.0 & 6.6 & 0.7 & 44.9 & 23.0 & 280.9 & 3.5 & 0.8 & 27.5 & 4.8 & 2.2 \\
\hline Min & 22.91 & 0.11 & 0.10 & 1.00 & 1.62 & 0.17 & 0.80 & 0.41 & 21.65 & 0.27 & 0.00 & 1.00 & 0.33 & 0.30 \\
\hline
\end{tabular}

Abu Qir Sector from 1 - 15; Eastern Harbour sector: 16 - 28, Western Harbour sector: 29 - 39, El Max sector: 40 - 49, Av: average, Max: maximum, Min: minimum, PAHs: Sum of aromatic hydrocarbons, Phe: phenanthrene, An: anthracene, Flu: Fluoranthene, Py: pyrene, BaA: Benzo(a)anthracene, Chr: Chrysene, BkF: benzo(k)flouranthene, BaP: benzo(a)pyrene, BbF: benzo(b)fluoranthene, $\Sigma$ CARC: Sum of BaA $+\mathrm{BbF}+\mathrm{BkF}+\mathrm{BaP}+\mathrm{DBA}+\mathrm{InP}, \Sigma \mathrm{TFPAH}$ : Sum Acenaphthylene + Acenaphthene, $\Sigma$ COMP: Sum of all PAHs except those calculated for $\Sigma$ TFPAH. 
Table 2. Concentrations (ng/g; dry wt) of individual PAHs in sediment samples during 2010.

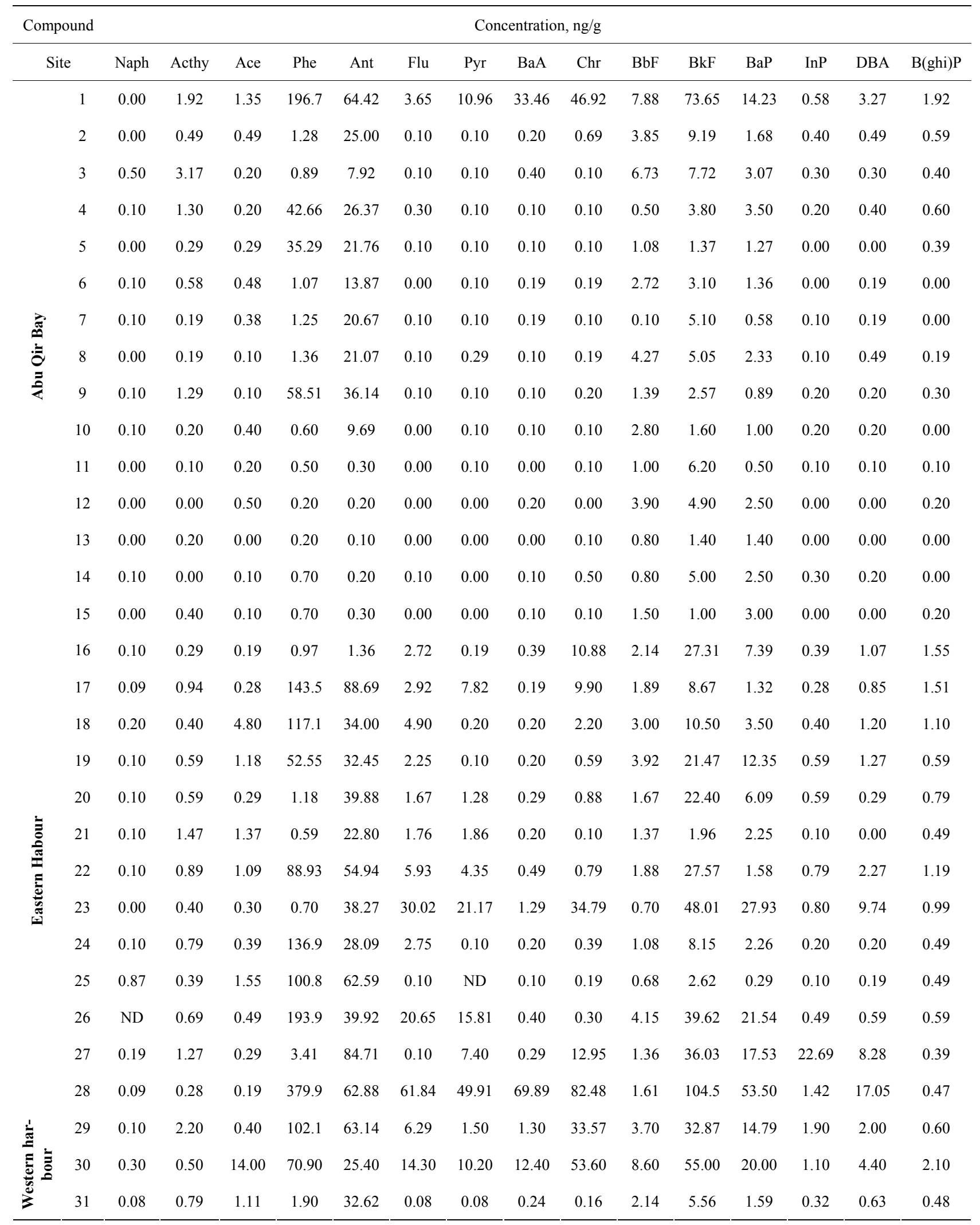




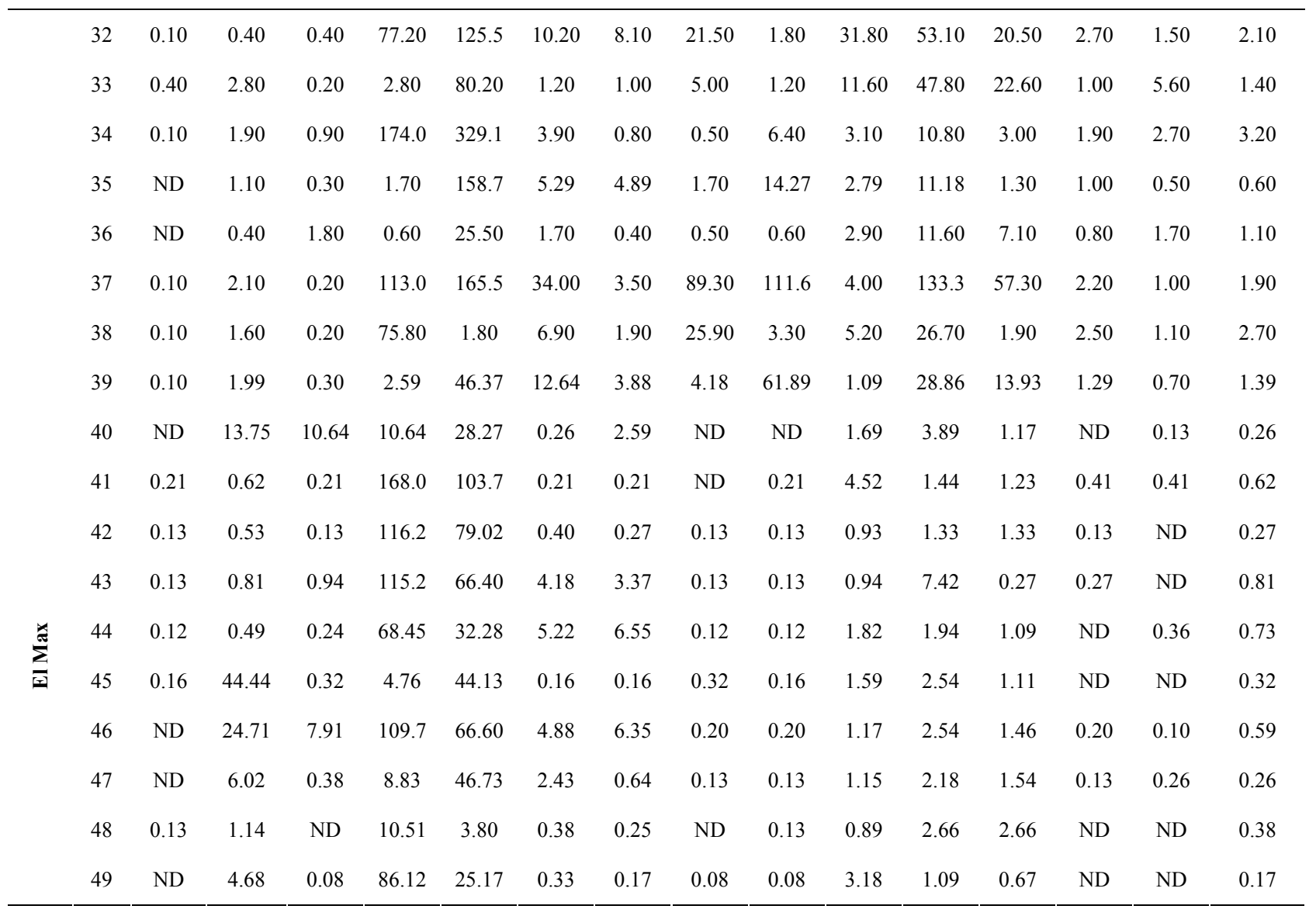

Table 3. ERL and ERM for PAHs recorded in sediment according to Long et al. [11].

\begin{tabular}{ccc}
\hline Component, ng/g & ERL & ERM \\
\hline Acenaphthene & 16 & 500 \\
Acenaphthylene & 44 & 640 \\
Anthracene & 85.3 & 1100 \\
Fluorene & 19 & 540 \\
Naphthalene & 160 & 2100 \\
Phenanthrene & 240 & 1500 \\
BaA & 261 & 1600 \\
BaP & 430 & 1600 \\
Chrysene & 384 & 2800 \\
Dibenzo(a,h)Anthracene & 63.4 & 260 \\
Fluoranthene & 600 & 5100 \\
Pyrene & 665 & 2600 \\
Total PAHs & 2967 & 20340
\end{tabular}

$\overline{\mathrm{ERL}}=$ concentration at lower tength percentage at which adverse observed, $\mathrm{ERM}=$ concentration at which adverse effects were observed at $50 \%$ of test organisms.
( $\mathrm{PAHCARC)}$ [13] were highest at stations number 37 and 28 with 153.8 and $143.47 \mathrm{ng} / \mathrm{g}$, respectively (Table 1). BaP was ranged from 0.27 at station 43 to $57.30 \mathrm{ng} \cdot \mathrm{g}^{-1}$ at station 37 with a mean of $7.63 \mathrm{ng} \cdot \mathrm{g}^{-1}$, falling in the concentration range between rural and urban areas [14].

One difficulty in identifying PAH origins is the possible coexistence of many contamination sources, and the transformation processes that PAHs can undergo before deposition in the analyzed sediments. Nevertheless, some compounds could exhibit comparable evolution kinetics that could be used to identify the origin of organic matter in the environment [15]. The compounds of pyrene, phenanthrene and benzo(b)fluoranthene are components of fossil fuels and a portion of them is associated with their combustion. Benzo(a)pyrene is usually emitted from catalyst and no catalyst automobiles. Benzo(a)anthracene and chrysene are often resulted from combustion of both diesel and natural gas [16]. The ratio of sum of major combustion specific compounds ( $\mathrm{COMB}$, Flu, Pyr, $\mathrm{BaA}, \mathrm{Chr}, \mathrm{BbF}, \mathrm{BkF}, \mathrm{BaP}, \mathrm{InP}$ and BghiP) to the sum of 16 EPA-PAHs $\left(\sum \mathrm{COMB} / \sum \mathrm{PAHs}\right)$ were ranged from 0.55 to 1.0 and the $\sum \mathrm{COMB}$ concentrations displayed values from 4 to $885.5 \mathrm{ng} \cdot \mathrm{g}^{-1}$ (Table 1), representing average of $96 \%$ of total anthropogenic PAHs. This ratio 


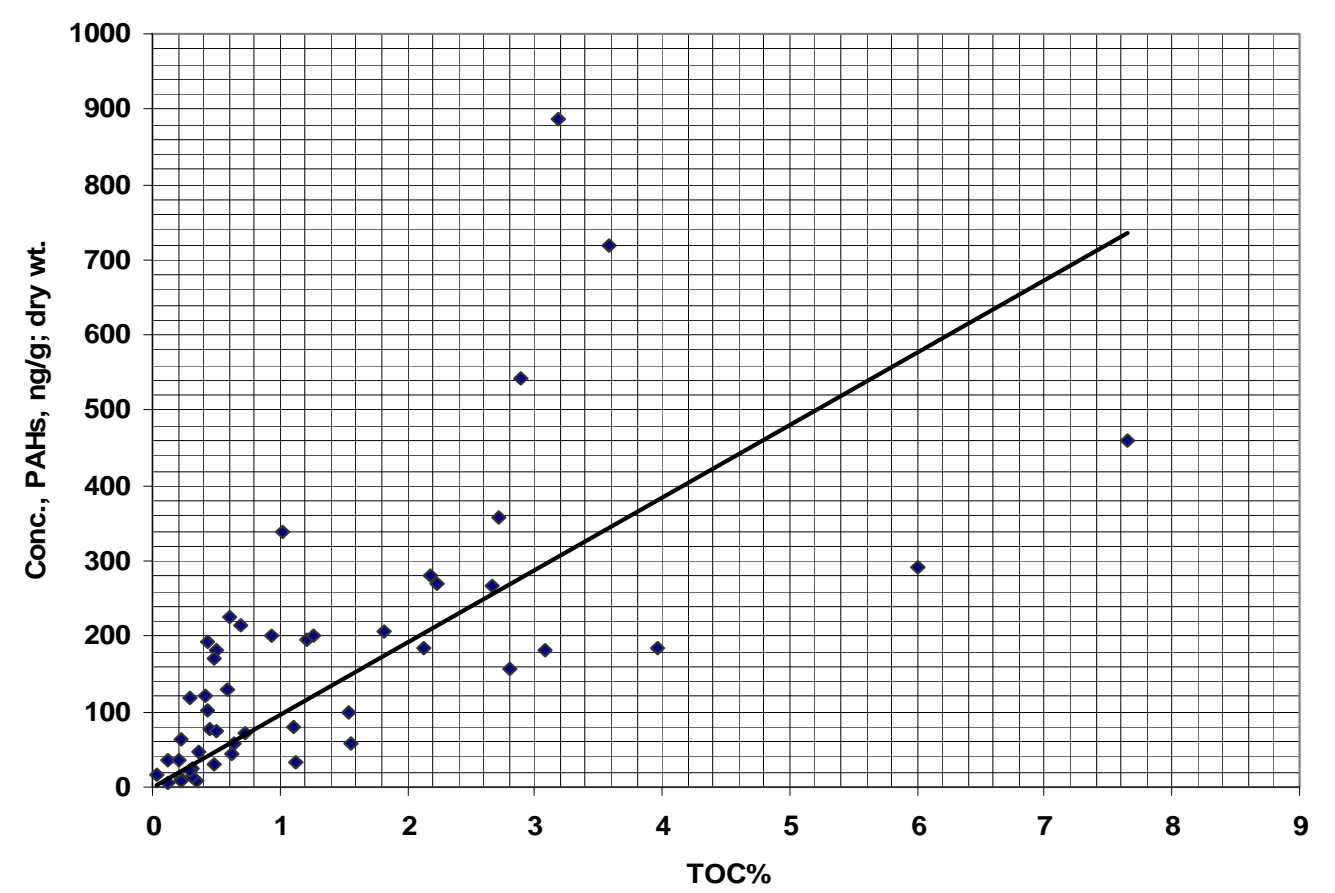

Figure 2. A plot of total PAHs concentration (ng/g; dry wt) vs. \% TOC of the sediments collected from the studied sediments $(r=0.646)$.

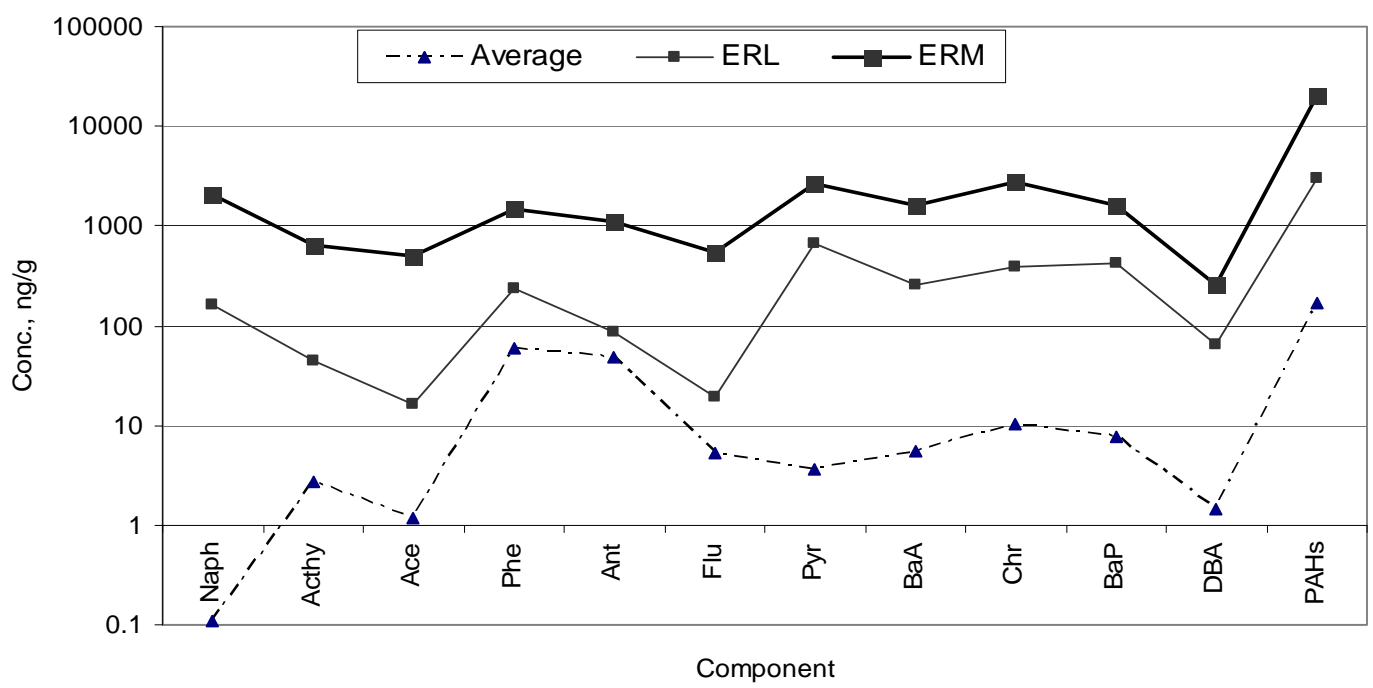

Figure 3. Diagram showed the average concentration $\left(\mathrm{ng}^{-1} \mathrm{~g}^{-1}\right.$; dry wt) of PAH in Mediterranean Sea sediments relative to ERL and ERM.

was 1 at stations 17, 23, 26 and 28 (Eastern Harbour); stations 32, 37 (Western Harbour); stations 41 and 42 (El Max Bay), which indicated that the PAHs at these sites manly come from combustion origin. The higher $\sum \mathrm{COMB} / \sum \mathrm{PAHs}$ ratio values further indicated that extensive combustion activities affected the PAHs in sediment samples. The sources of PAHs, where from fuelcombustion (pyrolytic) or from crude oil (petrogenic) contamination, may be identified by ratios of individual PAH compounds based on peculiarities in PAH composition and distribution pattern as a function of the emission source [17]. Ratio values such as phenanthrene/anthracene (Phe/Ant) and fluoranthrene/pyrene (Flu/Pyr) had been used by previous workers [18]. Petroleum often contains more phenanthrene relative to anthracene as phenanthrene that is more a thermodynamically stable 


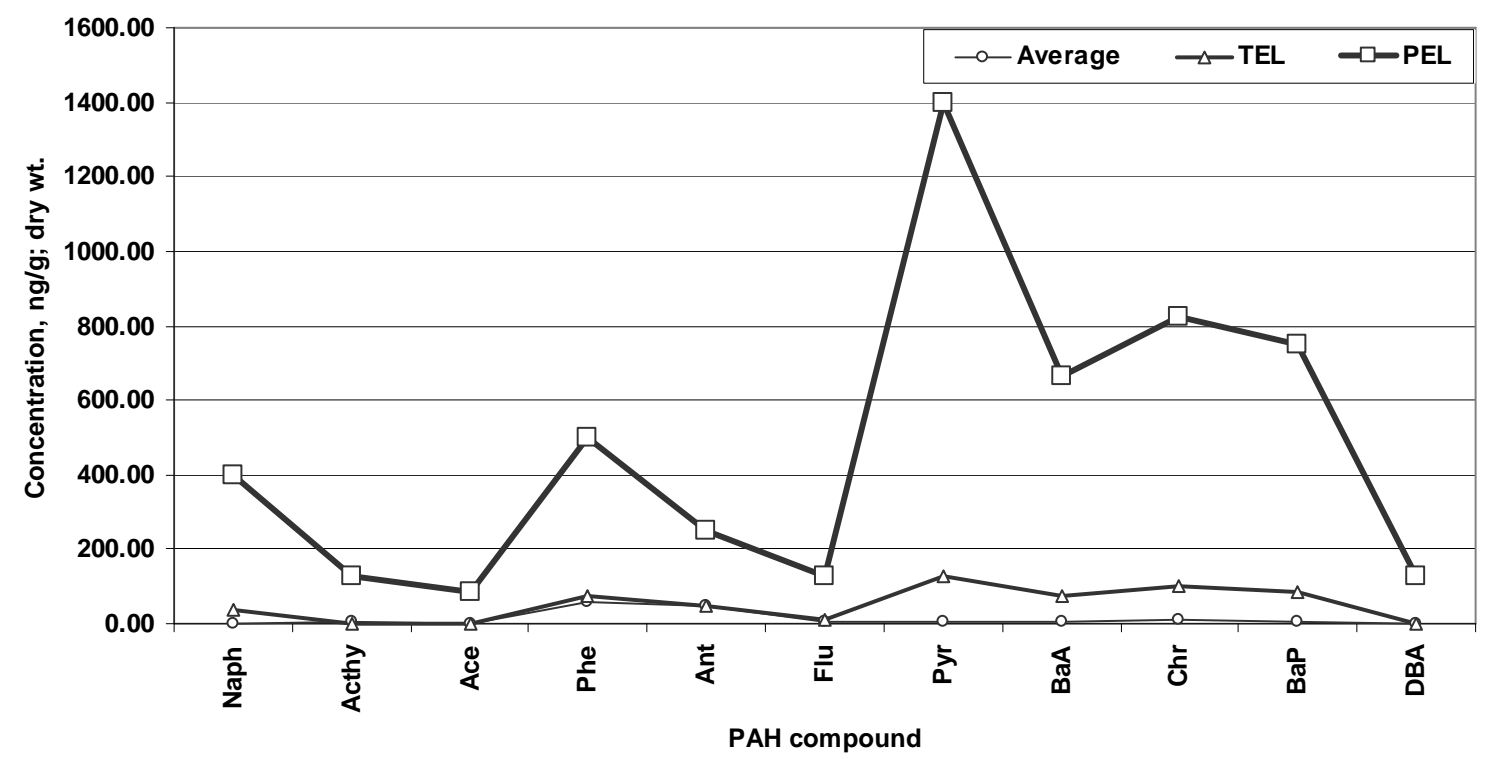

Figure 4. Diagram showed the average concentration $\left({\left.\mathrm{ng} \cdot \mathrm{g}^{-1}\right)}^{-1}\right.$ of average PAH components in sediment samples Threshold Effect Level (TEL) and Probable Effect Level (PEL).

tricyclic aromatic isomer than anthracene, so a Phe/Ant ratio is observed to be very high in PAH petrogenic pollution, but low ratio in pyrolytic contamination cases. Crude oil had a Phe/Ant ratio of around 50, and motor vehicle exhaust had a ratio of around four [19]. Low Phe/Ant ratio values $(<10)$ indicated the major PAH input was from combustion of fossil fuel. Sediments with Phe/Ant $>10$ were mainly contaminated by petrogenic inputs and Phe/Ant $<10$ was typical of pyrolytic sources. In the present study, the ratio of Phe/Ant compounds was $<10$, reflecting pyrolytic derived PAHs except for station 38 (repairing ship station) which recorded Phe/Ant ratio $>10($ ratio $=42.11)$, indicating petrogenic derived PAHs in such station. In other sediments the Phe/Ant ratio values were around $0.01-6.04$ (Table 1), suggesting that they were pyrolytic-derived PAHs. On the other hand fluoranthene/pyrene (Flu/Pyr) ratio also indicated the origin of PAHs. Sicre et al. [20] suggested that a Flu/Pyr ratio of less than 1 was attributed to petrogenic sources and values greater than 1 were obviously related to a pyrolytic origin. Combustion of coal and wood gave Flu/Pyr ratios of 1.4 and 1, respectively, while crude oil and fuel oil had values of $0.6-0.9$ [20]. In the present study, most sites had Flu/Pyr ratio values more than 1 (Table 1).

The PAHs whose concentrations are susceptible of co-varying in the environment were identified in this study on the basis of the correlation factor values (Table 4). This statistical approach is based on the fact that each pollution source produces a characteristic PAH pattern; so, the correlations of all the individual PAHs can give an idea whether they all originate from the same source or not. A lack of correlation was noticed between anthracene and other PAHs ( $r=0.116$ to 0.304$)$. Significant correlations were noted between Flu-Phe $(\mathrm{r}=0.602)$, Flu-Pyr $(\mathrm{r}=0.882)$, Flu-BaA $(\mathrm{r}=0.759)$, Pyr-Phe $(\mathrm{r}=$ $0.645)$, \%TOC-Phe $(\mathrm{r}=0.458)$, \%TOC-BaA $(\mathrm{r}=534)$, \%TOC-Chr $(\mathrm{r}=0.629), \%$ TOC-BKF $(\mathrm{r}=0.669)$, \%TOCBghiP $(r=0.697)$. These indicated that Flu, Phe, Pyr, $\mathrm{BaA}$ and $\mathrm{Chr}$ might originate from the same sources. Chrysene and benzo(a)anthracene are derived from processes of organic matter combustion at high temperature, with values of $\mathrm{Chr} / \mathrm{BaA}$ ratio lower than 1 . In contrast, low maturation of organic matter during burial in the sedimentary matrix could lead to an inversion of this tendency: $\mathrm{Chr} / \mathrm{BaA}=1$ [18]. It has been shown that chrysene derivatives are more stable than benzanthracenic ones because of the possibility of the latter ones to convert to chrysene compounds.

\section{Conclusions}

The present work represents the detailed study of the distribution and origin of petroleum hydrocarbons in 49 sediment samples collected from the semi-closed areas along the semi-closed areas of Alexandria, Egypt. The studied samples were less contaminated by petroleum hydrocarbons. Concentrations of PAHs in Mediterranean Sea sediments are shown to be substantially lower than those from other coastal areas and are generally comparable to levels encountered in the other Mediterranean Sea coast. The most contaminated site $\left(886 \mathrm{ng} \cdot \mathrm{g}^{-1}\right)$ was the Eastern Harbor (station 28). A mixture of pyrolytic 
Table 4. Correlation coefficient matrix for sediment individual PAHs $(n=49)$.

\begin{tabular}{|c|c|c|c|c|c|c|c|c|c|c|c|c|c|c|c|}
\hline Compound & Naph & Acthy & Ace & Phe & Ant & Flu & Pyr & $\mathrm{BaA}$ & $\mathrm{Chr}$ & $\mathrm{BbF}$ & $\mathrm{BkF}$ & $\mathrm{BaP}$ & $\mathrm{InP}$ & DBA & $\mathrm{B}$ (ghi)P \%TOC \\
\hline Naph & 1 & & & & & & & & & & & & & & \\
\hline Acthy & -0.028 & 1.000 & & & & & & & & & & & & & \\
\hline Ace & 0.084 & 0.245 & 1.000 & & & & & & & & & & & & \\
\hline Phe & 0.065 & -0.065 & 0.046 & 1.000 & & & & & & & & & & & \\
\hline Ant & 0.072 & 0.027 & -0.042 & $0.406^{*}$ & 1.000 & & & & & & & & & & \\
\hline Flu & -0.073 & -0.084 & 0.032 & $0.602^{* * *}$ & 0.208 & 1.000 & & & & & & & & & \\
\hline Pyr & -0.087 & -0.055 & 0.072 & $0.645^{* * *}$ & 0.116 & $0.882^{* * *}$ & 1.000 & & & & & & & & \\
\hline $\mathrm{BaA}$ & -0.022 & -0.060 & -0.023 & $0.517^{* *}$ & 0.274 & $0.759^{* * *}$ & $0.547^{* * *}$ & 1.000 & & & & & & & \\
\hline $\mathrm{Chr}$ & -0.016 & -0.082 & 0.115 & $0.409^{*}$ & 0.275 & $0.775^{* * *}$ & $0.561^{* * *}$ & $0.828^{* * *}$ & 1.000 & & & & & & \\
\hline $\mathrm{BbF}$ & 0.106 & -0.079 & 0.067 & 0.080 & 0.229 & 0.073 & 0.079 & 0.223 & 0.046 & 1.000 & & & & & \\
\hline $\mathrm{BkF}$ & 0.015 & -0.126 & 0.048 & $0.472^{* *}$ & 0.304 & $0.794^{* * *}$ & $0.625^{* * *}$ & $0.880^{* * *}$ & $0.865^{* * *}$ & 0.338 & 1.000 & & & & \\
\hline $\mathrm{BaP}$ & 0.016 & -0.113 & 0.010 & $0.442^{* *}$ & 0.269 & $0.869^{* * *}$ & $0.688^{* * *}$ & $0.827^{* * *}$ & $0.843^{* * *}$ & 0.261 & $0.945^{* * *}$ & 1.000 & & & \\
\hline InP & 0.085 & -0.059 & -0.050 & -0.035 & 0.204 & 0.036 & 0.128 & 0.077 & 0.129 & 0.061 & 0.227 & 0.238 & 1.000 & & \\
\hline DBA & 0.055 & -0.114 & 0.033 & $0.455^{* *}$ & 0.174 & $0.747^{* * *}$ & $0.852^{* * *}$ & $0.470^{* *}$ & $0.530^{* *}$ & 0.075 & $0.629^{* * *}$ & $0.699^{* * *}$ & $0.394^{*}$ & 1.000 & \\
\hline B(ghi)P & 0.084 & -0.100 & 0.172 & 0.320 & $0.566^{* * *}$ & 0.248 & 0.132 & $0.374^{*}$ & $0.372^{*}$ & $0.440^{* *}$ & $0.485^{* *}$ & 0.321 & 0.086 & 0.193 & 1.000 \\
\hline$\% \mathrm{TOC}$ & 0.145 & -0.009 & 0.270 & $0.458^{* *}$ & $0.385^{*}$ & $0.358^{*}$ & 0.338 & $0.534^{* *}$ & $0.629^{* * *}$ & $0.419^{*}$ & $0.669^{* * *}$ & $0.503^{* *}$ & 0.106 & $0.378^{*}$ & $0.697^{* * *} 1.000$ \\
\hline
\end{tabular}

Correlations are significant at $* \mathrm{p}<0.05$ (low significant), $* * \mathrm{p}<0.01$ (moderate significant) and $* * * \mathrm{p}<0.001$ (high significant).

and petrogenic PAHs were observed with a major pyrolytic predominance.

\section{REFERENCES}

[1] U. Varanasi, "Metabolism of PAHs in the Aquatic Environment," CRC Press, Boca Raton, 1989.

[2] C. Porte and J. Albaiges, "Bioaccumulation Patterns of Hydrocarbons and Polychlorinated Biphenyls in Bivalves, Crustacean and Fishes," Archives of Environmental Contamination and Toxicology, Vol. 26, No. 3, 1993, pp. 273-281.

[3] P. Baumard, H. Budzinski and P. Garrigues, "Determination of Polycyclic Aromatic Hydrocarbons (Pahs) in Sediments and Mussels of the Western Mediterranean Sea," Environmental Toxicology \& Chemistry, Vol. 17, No. 5, 1998, pp. 765-776. doi:10.1002/etc.5620170501

[4] J. Y. Cho, J. G. Son, B. J. Park and B. Y. Chung, "Distribution and Pollution Sources of Polycyclic Aromatic Hydrocarbons (Pahs) in Reclaimed Tidelands and Tidelands of the Western Sea Coast of South Korea," Environmental Monitoring and Assessment, Vol. 149, No. 1-4, 2009, pp. 385-393. doi:10.1007/s10661-008-0214-9

[5] T. K. Benlahcen, A. Chaoui, H. Budzinski, J. Bellocq and P. Garrigues, "Distribution and Sources of Polycyclic Aromatic Hydrocarbons in Some Mediterranean Coastal
Sediment," Marine Pollution Bulletin, Vol. 34, 1997, pp. 298-305. doi:10.1016/S0025-326X(96)00098-7

[6] L. Sanchez-Garcia, J. Cato and O. Gustafsson, "Evaluation of the Influence of Black Carbon on the Distribution of Pahs in Sediments from along the Entire Swedish Continental Shelf," Marine Chemistry, Vol. 119, No. 1-4, 2010, pp. 44-51. doi:10.1016/j.marchem.2009.12.005

[7] J. Dachs, J. M. Bayona, J. Fillaux, A. Saliot and J. Albaiges, "Evaluation of Anthropogenic and Biogenic Inputs into the Western Mediterranean Using Molecular Markers," Marine Chemistry, Vol. 65, No. 3-4, 1999, pp. 195-210. doi:10.1016/S0304-4203(99)00002-X

[8] M. A. Khairy, "Risk Assessment of Polycyclic Aromatic Hydrocarbons in a Mediterranean Semi-enclosed Basin Affected by Human Activities (Abu Qir Bay, Egypt)," Journal of Hazardous Materials, Vol. 170, No. 1, 2009, pp. 389-397. doi:10.1016/j.jhazmat.2009.04.084

[9] UNEP/IOC/IAEA, "Determination of Petroleum Hydrocarbons in Sediments," Reference Methods for Marine Pollution Studies, UNEP, Vol. 20, 1992, p. 75.

[10] C. T. Chiou, S. E. Mc Groddy and D. E. Kile, "Partition Characteristics of Polycyclic Aromatic Hydrocarbons on Soils and Sediments," Environmental Science \& Technology, Vol. 32, No. 2, 1998, pp. 264-269. doi: $10.1021 / \mathrm{es} 970614 \mathrm{c}$

[11] E. R. Long, D. D. MacDonald, S. L. Smith and F. D. Calder, "Incidence of Adverse Biological Effects within 
Ranges of Chemical Concentrations in Marine and Estuarine Sediments," Environmental Management, Vol. 19, 1995, pp. 81-97. doi:10.1007/BF02472006

[12] USEPA, "Proposed Sediment Quality Criteria for the Protection of Benthic Organism. EPA-882-R-93-012, EPA- 882-R-93-013, EPA-882-R-93-014," US Environmental Protection Agency, Office of Water, Washington, DC, 1993.

[13] International Agency for Research on Cancer, "IARC Monographs on the Evaluation of the Carcinogenic Risk of Chemicals to Human. Polynuclear Aromatic Hydrocarbons, Part I, Chemical, Environmental, and Experimental Data," Agency for Research on Cancer, Lyons, Vol. 32, 1983, pp. 1-477.

[14] C. A. Menzie, B. B. Potocki and J. Santodonato, "Exposure to Carcinogenic PAHs in the Environment," Environmental Science \& Technology, Vol. 26, No. 7, 1992, pp. 1278-1284. doi:10.1021/es00031a002

[15] G. P. Yang, "Polycyclic Aromatic Hydrocarbons in the Sediments of the South China Sea," Environmental Polls, Vol. 108, No. 2, 2000, pp. 163-171. doi:10.1016/S0269-7491(99)00245-6

[16] W. F. Rogge, L. Hildemann, M. A. Mazurek, G. R. Cass and B. R. T. Simoneit, "Sources of Fine Organic Aerosol: 2. Noncatalyst and Catalyst-Equipped Automobiles and
Heavy Duty Diesel Trucks," Environmental Science \& Technology, Vol. 27, 1993, pp. 636-651. doi:10.1021/es00041a007

[17] P. M. Gschwend and R. A. Hites, "Fluxes of Polycyclic Aromatic Hydrocarbons to Marine and Lacustrine Sediments in the Northeastern United States," Geochim Cosmochim Acta, Vol. 45, 1981, pp. 2359-2367. doi:10.1016/0016-7037(81)90089-2

[18] H. H. Soclo, P. H. Garrigues and M. Ewald, "Origin of Polycyclic Aromatic Hydrocarbons (Pahs) in Coastal Marine Sediments: Case Studies in Cotonou (Benin) and Aquitaine (France) Areas," Marine Pollution Bulletin, Vol. 40, No. 5, 2000, pp. 387-396. doi:10.1016/S0025-326X(99)00200-3

[19] S. Y. N. Yang, D. W. Connell, D. W. Hawker and S. I. Kayat, "Polycyclic Aromatic Hydrocarbons in Air, Soil Land Vegetation in the Vicinity of an Urban Roadway," Science of the Total Environment, Vol. 102, 1991, pp. 229-240. doi:10.1016/0048-9697(91)90317-8

[20] M. A. Sicre, J. C. Marty, A. Saliot, X. Aparicio, J. Grimalt and J. Albaiges, "Aliphatic and Aromatic Hydrocarbons in Different Sized Aerosols over the Mediterranean Sea: Occurrence and Origin," ATM Environment, Vol. 21, 1987, pp. 2247-2259. doi:10.1016/0004-6981(87)90356-8 